\title{
Calculation Methods for the Heat Release Rate of Materials of Unknown Composition
}

\author{
HUBERT BITEAU ${ }^{1 / 2}$, THOMAS STEINHAUS ${ }^{1}$, ALBERT SIMEONI ${ }^{4}$, CHRISTOPHER $^{2}$ \\ SCHEMEL $^{3}$, GUY MARLAIR ${ }^{2}$, NICOLAS BAL ${ }^{1}$ and JOSE L. TORERO ${ }^{1}$ \\ ${ }^{1}$ BRE Centre for Fire Safety Engineering, University of Edinburgh, UK \\ ${ }^{2}$ Institut National de l'Environnement Industriel et des Risques, Verneuil en Halatte, France \\ ${ }^{3}$ Packer Engineering, Inc., Columbia, Maryland, USA \\ ${ }^{4}$ CNRS-SPE, UMR 6134, University of Corsica, Corte, France
}

\begin{abstract}
The Heat Release Rate (HRR) is a critical parameter to characterise a fire. Different methods have been developed to estimate it. The most widespread techniques are based on mass balance. If the heat of combustion of the fuel is known, the measure of the mass loss allows its evaluation. If the burning material cannot be identified, calorimetric principles can be used. They rely on oxygen consumption (OC) or carbon dioxide and carbon monoxide generation (CDG) measurements. Their asset comes from the observation that the amount of energy release per unit mass of $\mathrm{O}_{2}$ consumed or per unit mass of $\mathrm{CO}_{2}$ produced is relatively constant for a large number of materials. Thus, an accurate HRR can be obtained without knowing the composition of the burning fuel. The aim of this work is to assess this last statement and define how essential the knowledge of the chemistry to calculate HRR for complex materials such as polymers including fire retardants and/or nanocomposites, energetic materials or pine needles is. This assessment ends in an $\mathrm{OC}$ and CDG calorimetry comparison of several materials in order to investigate the propensity to determine whether converging or diverging HRR results when average energy constants are used.
\end{abstract}

KEYWORDS: heat release rate, calorimetry, fire chemistry, polymers, energetic materials, wildfires

\section{NOMENCLATURE LISTING}

$A$

E

$\Delta H$
$\Delta H_{c}$
$\Delta h_{\text {reaction }}^{0}$
$\Delta h_{\text {formation }}^{0}$
$K$
$\dot{m}$
$M$
$n$
$\dot{n}$
$\dot{q}$
$\dot{V}$

Cross section area of the exhaust duct, $\left(\mathrm{m}^{2}\right)$

Energy release by unit mass of $O C$

species consumed or generated, $C D G$ $(\mathrm{kJ} / \mathrm{g})$

Enthalpy variation, $(\mathrm{kJ})$

Heat of combustion, $\left(\mathrm{MJ}_{\mathrm{kg}} \mathrm{kg}^{-1}\right)$

Heat of reaction, $(\mathrm{kJ})$

Heat of formation, $(\mathrm{kJ})$

Pitot tube coefficient

Mass flow rate, $(\mathrm{g} / \mathrm{s})$

Molecular weight, (g/mol)

coefficient of chemical reaction

Mole flow rate, $(\mathrm{mol} / \mathrm{s})$

Heat release rate, $(\mathrm{kJ} / \mathrm{s})$

Exhaust volume flow, $\left(\mathrm{m}^{3} / \mathrm{s}\right)$

Subscript

$a$

e

$\mathrm{O}_{2}$

Hc

Mass Loss

convective

average

Average authors

literature

stochiometry

chemistry oxygen consumption calorimetry

carbon dioxide generation calorimetry

Incoming gases

Exhaust gases

$\mathrm{O}_{2}$ for oxidation of $\mathrm{CO}$ into $\mathrm{CO}_{2}$

by heat of combustion and mass loss

| Calculation from mass loss convective calculation

Calculation based on Huggett and Tewarson constants)

Calculation based on average values from authors

Calculation based on literature values

Calculation based on stoichiometry

Calculation based on chemistry 


$\begin{array}{llll}X & \text { Molar fraction } & i, j & \text { Species } \\ A & \text { Expansion factor } & \text { Superscript } & \\ \Phi & \mathrm{O}_{2} \text { depletion factor } & A & \text { Analyser measured value } \\ \rho & \text { Density, }\left(\mathrm{kg} / \mathrm{m}^{3}\right) & 0 & \text { Value before combustion }\end{array}$

\section{INTRODUCTION}

The Heat Release Rate (HRR) is a critical parameter for the evaluation of compartment fire growth that is incorporated to a wide range of fire assessment tools, ranging from simple hazard indexes to complex computational fluid dynamics modelling. Analytical formulations, empirical correlations, Zone and Computational Fluid Dynamics (CFD) models use the HRR as an input parameter to determine almost every other quantifiable variable with respect to the fire.

A series of methodologies have been developed to evaluate the HRR of materials and objects. These methodologies can use indirect measurements of temperature rise [1], mass loss, oxygen consumption or species production [2-3]. Furthermore, measurements can be made at the very small [4], intermediary [5] or realistic scale [6]. The most common methodology to establish the HRR is Oxygen Cosumption Calorimetry (OC). It was originally based on the observation that HRR is proportional to oxygen consumption during the combustion of most organic liquid and gaseous fuels [7]. The applicability of OC was eventually extended to organic solid fuels and an average value for the energy constant of $13.1+/-$ $0.68 \mathrm{MJ} . \mathrm{kg}-1$ of $\mathrm{O}_{2}$ consumed was found applicable for most organic substances [8]. The $0.68 \mathrm{MJ} . \mathrm{kg}^{-1}$ represents an uncertainty of $5 \%$ relative to the average energy constant of 13.1. An analysis of a larger series of liquids, gases and solids determined an average value of $12.8+/-0.9 \mathrm{MJ} / \mathrm{kg}$ of $\mathrm{O}_{2}$ consumed [ 9 ]. This represents a $7 \%$ uncertainty in the average value. The advantage of this methodology is that it allows estimating the HRR directly from measurements, without the knowledge of the material chemical composition or the combustion chemistry.

Several studies have discussed the errors associated with estimating HRR by means of OC and concluded that, for many materials, this approach is sufficient $[10,11]$, thus this practice is now in widespread use. Despite the general acceptance that $\mathrm{OC}$ is precise enough, certain complex materials merit the addition of other supplemental measurements $\left(\mathrm{CO}, \mathrm{CO}_{2}\right.$, Total Hydrocarbons) to enable a more precise reconstruction of the combustion chemistry [12]. A review of the general sources of uncertainty and the documents that address them is provided by Janssens [13]. Janssens emphasises that all sources of uncertainty can not be fully accounted for and Axelsson [11] indicates that given the potential sensitivity of fire assessment tools to the HRR, further analysis of uncertainty is required. The relative uncertainty related to the OC energy constant was determined to be $5 \%$. However, this result only considers the most common organic fuels. The analysis of the experimental data leading to the HRR involves uncertainty introduced from measurement errors, in addition to, a series of assumptions and approximations. Methodologies have been developed to address uncertainties in experimental data and, in turn, to estimate the propagation of uncertainty as it relates to contrived variables and other calculations using measured data. Several studies have shown that most experimental errors can be adequately quantified and, in general, do not affect the applicability of the HRR as input for fire safety calculations [10]. In contrast, the errors associated to the assumptions embedded in the calculation methodologies have received significant less attention. Currently, there is no systematic way of establishing how the nature of the material tested can affect the validity of the assumptions and consequently how much detail is necessary to obtain an estimation of the HRR that is consistent with the complexity and required precision of the fire safety analysis.

In this study the HRR obtained from several different calculation methodologies was compared for a number of fuels that range, with respect to their composition, combustion reaction and available information, from fairly simple (methane) to the very complex (pine needles). Since the exact HRR for the test specimens is not known, the authors assume, if the appropriate methodologies with similar assumptions (e.g. determination of energy constants) are chosen and these provide very comparable HRR curves, that they then resemble the best achievable result for the HRR curves. The results are then compared to show their applicability. 


\section{HRR PRINCIPLES}

\section{Mass Loss}

Different techniques have been developed to evaluate the HRR. When the heat of combustion of the material is known, a good evaluation of the theoretical HRR can be obtained by measuring the burning rate. The HRR is then given by the following expression:

$\dot{q}_{H c}=\Delta H_{c} \dot{m}_{f u e l}$

In case of complete combustion, the only measurement required is the mass loss. An uncertainty analysis leads to an error lower than $10 \%$ [14]. Nevertheless, it will increase when the reaction tends to become incomplete. The production of $\mathrm{CO}$ releases less energy than the generation of $\mathrm{CO}_{2}$ per gram of fuel burnt. Assuming complete combustion would lead to an overestimation of the HRR. A correction of the heat of combustion can be introduced taking into account the $\mathrm{CO} / \mathrm{CO}_{2}$ ratio. The advantage of this technique is that few parameters are necessary, which reduces the propagation of uncertainty. Nevertheless, the main challenge is that the procedure involves the knowledge of the burning material and its heat of combustion.

\section{Convective calorimetry}

Conducting an energy balance of the combustion products, the HRR rate can be established from temperature measurements [15]. The basic equation for calculating the convective HRR is given by,

$Q_{\text {convective }}=\dot{m}_{e} c_{p_{\text {air }}} \Delta T$.

Two measurements are required: the mass flow of combustion products and the variation of temperature through the calorimeter. A major issue impacting uncertainty of the technique is that the heat loss terms are difficult to define accurately. Smith proposed an expression taking account of the transient heat exchange between the air stream and the calorimeter apparatus [15]. However, it entails significant additional temperature measurements and calibration factors to be determined.

\section{Species based calorimetry}

A different approach is to determine the HRR from species concentration measurements. The method relies on a mass balance instead of the thermal one mentioned previously. Given that the flow is contained within the exhaust system, this procedure has the potential for higher accuracy. The most widespread method is based on oxygen mass balance (OC). Another technique based on $\mathrm{CO}_{2}$ and $\mathrm{CO}$ mass balance has also been developed and is known as Carbon Dioxide Generation Calorimetry (CDG). The two principles are widely used by researchers for fire test applications. More sophisticated methods can be achieved by including further species. They lead to some form of reconstruction of the combustion chemistry based on a comprehensive species mass balance. Currently, the Cone Calorimeter [2, 3] is the most frequently used instrument for species based calorimetry. However, the FM-Global Fire Propagation Apparatus (FPA) [16], which is based on the same principles, provides a more controlled environment, thus has been be used in this study.

The basic hypothesis to estimate HRR by species calorimetry hinges on the knowledge of the evolution of combustion gases concentration. The stoichiometric reaction of complete combustion for a chemical $\mathrm{C}_{x} \mathrm{H}_{y} \mathrm{O}_{z}$ is given by:

$$
C_{x} H_{y} O_{z}+\left(x+\frac{y}{4}-\frac{z}{2}\right)\left(O_{2}+3.76 N_{2}\right) \rightarrow x \mathrm{CO}_{2}+\frac{y}{2} H_{2} O+3.76\left(x+\frac{y}{4}-\frac{z}{2}\right) N_{2}
$$

Every mole of fuel combusted generates a certain amount of energy. Thornton showed that the heat release is proportional to the amount of oxygen consumed for complete combustion [4]. This statement 
suggests that variations in $\mathrm{O}_{2}$ concentration and a constant of heat released per unit mass of $\mathrm{O}_{2}$ consumed are sufficient to estimate the HRR of a complete combustion reaction. Following this reasoning, the OC principle can be expressed by:

$\dot{q}_{o c}=E_{O_{2}}\left(\dot{m}_{O_{2}}^{0}-\dot{m}_{O_{2}}\right)-\left(E_{O_{2}\left(C O \rightarrow C O_{2}\right)}-E_{O_{2}}\right) \dot{m}_{O_{2}\left(C O \rightarrow C O_{2}\right)}$

$E_{\mathrm{O}_{2}}$ proves to be approximately constant for a large number of organic solids, liquids and gaseous compounds allowing such a calculation even when detailed chemistry of the materials of interest is unknown. Huggett underlined that the process occurring during the combustion of these materials is mainly the breaking of $\mathrm{C}-\mathrm{C}, \mathrm{C}-\mathrm{H}$ and $\mathrm{O}=\mathrm{O}$ bonds which requires approximately the same amount of energy and the formation of $\mathrm{C}=\mathrm{O}$ and $\mathrm{O}-\mathrm{H}$ bonds which releases heat. Huggett obtained an average value for $E_{\mathrm{O}_{2}}$ of $13.1 \mathrm{MJ} . \mathrm{kg}-1$ of $\mathrm{O}_{2}$ consumed [5]. With standard fuels, the accuracy of the constant is within \pm $5 \%$. The second term of equation (4) is a correction accounting for incomplete combustion, relying on the amount of $\mathrm{O}_{2}$ that would have been necessary to oxidize $\mathrm{CO}$ into $\mathrm{CO}_{2}$.

The other principle (CDG) is based on carbon dioxide and carbon monoxide generation instead of oxygen consumption. Tewarson [9] showed that for many organic gaseous, liquid compounds and solids, the energy release per unit mass of $\mathrm{CO}_{2}$ produced was relatively constant. He found a value of $E_{\mathrm{CO}_{2}}=13.3$ MJ.kg ${ }^{-1}$ of $\mathrm{CO}_{2}$ within a range of $\pm 11 \%$. He also showed that the heat release per unit mass of $\mathrm{CO}$ generated was also virtually constant with a value of $E_{\mathrm{CO}_{2}}=11.1 \mathrm{MJ} . \mathrm{kg}-1$ of $\mathrm{CO} \pm 18 \%$. This relationship is given by:

$$
\dot{q}_{C D E}=E_{C O_{2}}\left(\dot{m}_{C O_{2}}-\dot{m}_{C O_{2}}^{0}\right)+E_{C O} \dot{m}_{C O}
$$

For a well ventilated fire, both principles require at least two measurements: the mass flow rate of the exhaust gases and an accurate estimation of the $\mathrm{O}_{2}(\mathrm{OC})$ or $\mathrm{CO}_{2}(\mathrm{CDG})$ concentration. Janssens and Parker [17, 18] provide the complete expressions to estimate the HRRs. From Equations (4) and (5) one arrives at the following two equations (6) for $\mathrm{OC}$ and (7) for $\mathrm{CDG}$,

$$
\begin{aligned}
& \dot{q}_{o c}=\left[E_{\mathrm{O}_{2}} \phi-\left(E_{\mathrm{O}_{2}\left(\mathrm{CO} \rightarrow \mathrm{CO}_{2}\right)}-E_{\mathrm{O}_{2}}\right)\left(\frac{1-\phi}{2}\right) \frac{X_{C O}^{A}}{X_{\mathrm{O}_{2}}^{A}}\right] X_{O_{2}}^{A^{0}}\left(1-X_{\mathrm{H}_{2} \mathrm{O}}\right) \frac{M_{\mathrm{O}_{2}}}{M_{e}} \frac{\dot{m}_{e}}{1+\phi(\alpha-1)} \\
& \dot{q}_{C D O}=\frac{\dot{m}_{e}}{M_{e}}\left(1-X_{\mathrm{H}_{2} \mathrm{O}}\right)\left(E_{\mathrm{CO}_{2}} X_{C O_{2}}^{A} M_{C O_{2}}+E_{C O} X_{C O}^{A} M_{C O}\right)-\frac{\dot{m}_{a}}{M_{a}}\left(1-X_{\mathrm{H}_{2} \mathrm{O}}^{0}\right) E_{\mathrm{CO}_{2}} X_{C O_{2}}^{A^{0}} M_{C O_{2}}
\end{aligned}
$$

Several assumptions are required to conduct these calculations [17, 18]. All gases are considered to behave as ideal gases. Entrained air is only considered as $\mathrm{N}_{2}, \mathrm{O}_{2}, \mathrm{CO}_{2}$ and $\mathrm{H}_{2} \mathrm{O}$. Combustion gases consist only of $\mathrm{N}_{2}, \mathrm{O}_{2}, \mathrm{CO}_{2}, \mathrm{CO}$ and $\mathrm{H}_{2} \mathrm{O}$ and THC. The later is not part of equations (6) and (7).

Prior performing the measurements, the combustion exhaust gases are dried. Relative humidity in the incoming air will be measured in order to estimate the actual species molar fractions $\left(X_{i}=\left(1-X_{\mathrm{H}_{2} \mathrm{O}}\right) X_{i}^{A}\right)$. The water vapour produced during the combustion can be measured with an infrared analyser or estimated if the chemical reaction can be described. Otherwise, it is not estimated in the calorimetry calculation (i.e. $X_{\mathrm{H}_{2} \mathrm{O}}=X_{\mathrm{H}_{2} \mathrm{O}}^{0}$ ). All inert gases are regarded as $\mathrm{N}_{2}$. They are assumed not to participate in the combustion reaction. The mass flow of $\mathrm{N}_{2}$ entering the system and in the exhaust gases is assumed to be conserved $\left(\dot{n}_{N_{2}}^{0}=\dot{n}_{N_{2}}\right)$. A relation between incoming and exhaust mass flow rates can be defined from the nitrogen conservation assumption. It is given by: 
$\frac{\dot{m}_{a}}{M_{a}}=\frac{\dot{m}_{e}}{M_{e}} \frac{\left(1-X_{H_{2} O}\right)\left(1-X_{O_{2}}^{A}-X_{C O_{2}}^{A}-X_{C O}^{A}\right)}{\left(1-X_{H_{2} O}^{0}\right)\left(1-X_{O_{2}}^{A^{0}}-X_{C O_{2}}^{A^{0}}\right)}$

The flow rate is inferred from the following relation where the exhaust gases velocity is measured by mean of a Pitot tube or equivalent.

The parameter $\phi$ in equation (6) is defined as the depletion factor. It is the fraction of the incoming air that is fully depleted of its oxygen during the combustion process. It is given by the expression:

$\phi=\frac{\dot{n}_{O_{2}}^{0}-\dot{n}_{O_{2}}}{\dot{n}_{O_{2}}^{0}}=\frac{Y_{O_{2}}^{A^{0}}\left(1-X_{C O_{2}}^{A}-X_{C O}^{A}\right)-X_{O_{2}}^{A}\left(1-X_{C O_{2}}^{A^{0}}\right)}{X_{O_{2}}^{A^{0}}\left(1-X_{O_{2}}^{A}-X_{C O_{2}}^{A}-X_{C O}^{A}\right)}$

$\alpha$ is the expansion factor. During a combustion reaction, a fraction of the incoming air is depleted of its oxygen and is replaced by an equal or larger number of moles of combustion products. The expansion factor is the ratio of these two molar quantities. It is given by:

$$
\alpha=1+X_{O_{2}}^{A^{0}}\left(1-X_{H_{2} O}^{0}\right)(\beta-1) \quad \text { (10) } \quad \text { and } \quad \beta=\frac{\sum n_{\text {stoichio products }}}{n_{\text {stoichio } O_{2}}}
$$

The major advantage of OC and CDG is that they allow estimating the HRR of an unknown material when using the average energy constants. They both have shown their ability to predict HRR accurately for standard fuels, polymers or chemicals [5]. However, the calculations involve several assumptions and the estimates of different parameters that can lead to the propagation of uncertainties. Combining the two principles, may present noticeable advantages. Divergence of the results would underline that the assumptions of at least one of the calculations is not valid, when burning the studied material under defined test conditions.

Among the different approaches available, mass loss and calorimetric methods (CONV, OC, CDG) allow to obtain accurate HRR results. It has previously been noted, when using the mass loss technique that the heat of combustion of the burning material needs to be known. Calorimetric principles can provide accurate results without information on the material. Nevertheless, the accuracy of the thermal balance principle highly depends on the estimation of the heat losses. Nowadays, HRR estimations usually rely on OC and CDG methods although uncertainty studies $[10,11,12]$ have underlined that using average energy constants rather than actual values can significantly affect the accuracy of the results. The heat of combustion is a critical material characteristic for the fire safety community as well as a necessary parameter to estimate energy constants but unfortunately not sufficient.

\section{Heat of Combustion and Energy constants}

The values of energy constants defined by Huggett [5] and Tewarson [9] appear adequate for measuring HRR when materials are known. However, for any known material the energy constant can also be calculated from the heat of combustion $\Delta \mathrm{H}_{\mathrm{c}}$. The heat of combustion is determined by the heat of formation of each molecule for the combustion reaction or determined experimentally using a bomb calorimeter.

If the fuel and its heat of formation are known, then a heat of reaction can be estimated given the chemical reaction equation. The heat of reaction will be:

$$
\Delta h_{\text {reaction }}^{0}=\sum_{\text {product } i} \Psi_{i} \Delta h_{\text {formation } i}^{0}-\sum_{\text {reactan } t j} \Psi_{j} \Delta h_{\text {formation } j}^{0}
$$


For a complete combustion reaction, the heat of reaction is defined as the heat of combustion at the conditions of pressure and temperature of 1 atmosphere and $298 \mathrm{~K}$. If the water produced is considered as vapour, then the amount of energy released is equal to the net heat of combustion of the burning material.

For a fuel with an unknown heat of formation, the gross heat of combustion is measured using an oxygen bomb calorimeter [19]. Once the gross heat of combustion has been determined, the net heat of combustion can be calculated, by subtracting the latent heat of water at $298 \mathrm{~K}$ (by estimating the mass fraction of hydrogen in the fuel). Energy constants for OC and CDG are related to the heat of combustion. It can be compared to a change of bases. The heat release is estimated in $\mathrm{OC}$ by taking a unit mass of $\mathrm{O}_{2}$ consumed or in $\mathrm{CDG}$ by $\mathrm{CO}_{2} / \mathrm{CO}$ as reference instead of a unit mass of the burning fuel. Two alternative methods to evaluate energy constants are presented in this study: the first based on the stoichiometric reaction. The second method calculates the energy coefficients of the chemical reaction from the measurements of species concentration $\left(\mathrm{O}_{2}, \mathrm{CO}_{2}\right.$ and $\left.\mathrm{CO}\right)$.

\section{Energy constants estimated from the equation of stoichiometric reaction}

Given the chemical equation, following the assumption of a complete combustion and if the fuel composition is known, the energy constants can be estimated, using the following expressions (13) for OC and $(14,15)$ for $\mathrm{CDG})$ :

$$
E_{O_{2 s t}}=\frac{\Delta H_{c f u e l} M_{\text {fuel }}}{\left(x+\frac{y}{4}-\frac{z}{2}\right) M_{O_{2}}}
$$

$$
E_{\mathrm{CO}_{2} \mathrm{st}}=\frac{\Delta H_{c f \text { fuel }} M_{\text {fuel }}}{x M_{\mathrm{CO}_{2}}}
$$

$$
E_{\mathrm{COSt}}=\frac{E_{\mathrm{CO}_{2}} M_{\mathrm{CO}_{2}}-\Delta H_{\mathrm{CO}}}{x}
$$

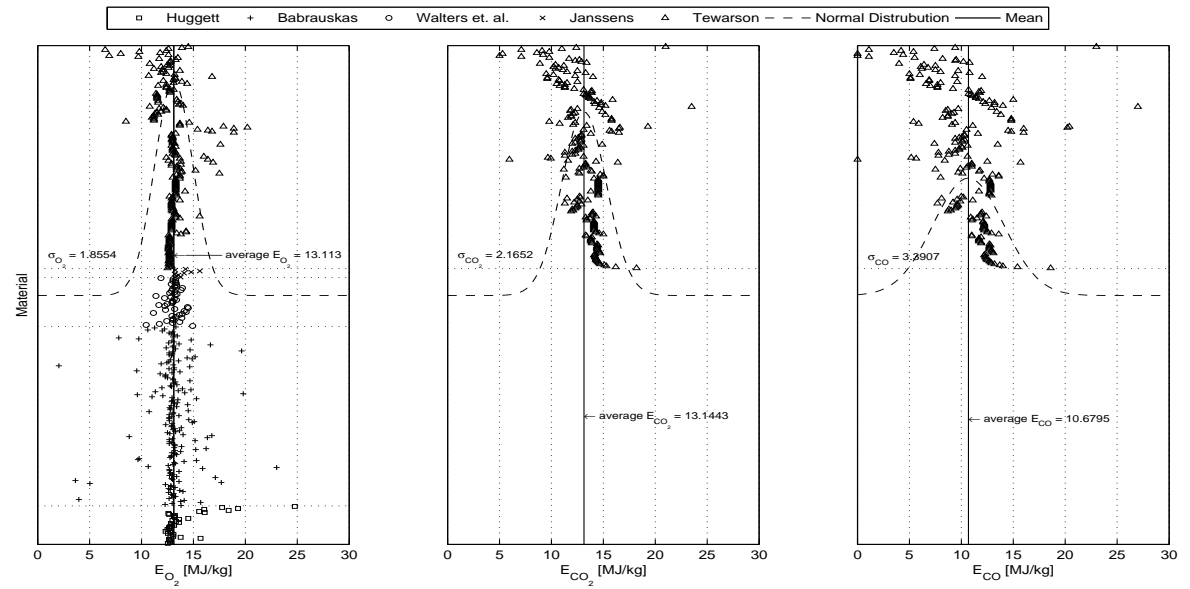

Fig. 1. Energies releases per unit mass of oxygen consumed (left graph), carbon dioxide produced (middle graph) and carbon monoxide produced (right graph) of various materials found in the literature Huggett [5], Babrauskas [15], Walters et. al. [18], Janssens [19], Tewarson [9].

Constants obtained through this calculation method will be referred to as stoichiometric energy constant. For well ventilated fires, using these quantities instead of the averaged ones allows reducing the error on the HRR results. They are available in the literature [5, 9, 17, 20 and 21]. Fig. 1 shows $E_{\mathrm{O}_{2}}, E_{\mathrm{CO}_{2}}$ and $E_{C O}$ values for a large number of various materials from the literature. They encompass organic liquids and gases [5, 9], synthetic polymers [20] and natural fuels [16]. It has to be noted that materials found in the literature have been listed irrespective of their possible double occurrence. Four fuels have been ignored lying well outside the range of $0-30 \mathrm{MJ} / \mathrm{kg}$ considered in this work. 
Table 1. Mean and standard deviation of energy release rates.

\begin{tabular}{|c|c|c|c|}
\hline $\begin{array}{c}\text { Energy release per unit } \\
\text { mass of } \mathrm{O}_{2}, \mathrm{CO}_{2}, \mathrm{CO}\end{array}$ & $\begin{array}{c}\text { Average value } \\
(\mathrm{MJ} / \mathrm{kg})\end{array}$ & $\begin{array}{c}\text { Standard Deviation } \\
(\mathrm{MJ} / \mathrm{kg})\end{array}$ & Standard Deviation (\%) \\
\hline$E_{\mathrm{O}_{2}}$ & 13.1 & 1.86 & 14 \\
\hline$E_{\mathrm{CO} O_{2}}$ & 13.1 & 2.17 & 16.5 \\
\hline$E_{\mathrm{CO}}$ & 10.7 & 3.39 & 31.7 \\
\hline
\end{tabular}

Furthermore, the mean values of the three different energy release rates and their normal distribution are therein presented. The mean values and standard deviation are given in Table 1. The average energy constants obtained are consistent with the values defined by Huggett $\left(E_{\mathrm{O}_{2}}\right)$ and Tewarson $\left(E_{\mathrm{CO}_{2}}, E_{\mathrm{CO}}\right)$. However, the standard deviations are larger due a larger distribution of the constants. Average values from Table 1 will be taken as reference in this paper.

\section{Energy constants estimated from the reaction chemistry}

The main assumption to calculate the constants on the basis of the previous principle is that the chemistry follows a complete combustion reaction. Ventilation conditions during burning or the condition of the burning material (for example the presence of nanocomposites, fire retardants or oxidizer inside the matrix), can cause the chemical reaction to diverge significantly from a complete combustion process. For these kinds of products, the heat of combustion can still be estimated through bomb calorimeter tests. Furthermore, a combustion reaction can be chemically described with the following equation (in the studied case, all THC are lumped into $\mathrm{CH}_{4}$ in order to simplify the mechanism):

$$
\mathrm{C}_{x} \mathrm{H}_{y} \mathrm{O}_{z}+n_{1}\left(\mathrm{O}_{2}+3.76 \mathrm{~N}_{2}\right) \rightarrow n_{2} \mathrm{CO}_{2}+n_{3} \mathrm{CO}+n_{4} \mathrm{H}_{2} \mathrm{O}+n_{5} \mathrm{THC}\left(\text { eq. } \mathrm{CH}_{4}\right)+3.76 n_{1} \mathrm{~N}_{2}
$$

Reaction coefficients $n_{1}, n_{2}, n_{3}, n_{4}, n_{5}$ can be estimated for an instant t:

$$
\begin{aligned}
& n_{1}(t)=\frac{\dot{n}_{O_{2}}(t) M_{f u e l}}{\dot{m}_{f u e l}}=\frac{\left(X_{O_{2}}^{A^{O}}\left(1-X_{H_{2} O}^{O}\right) \dot{n}_{a}-X_{O_{2}}^{A}\left(1-X_{H_{2} O}\right) \dot{n}_{e}\right) M_{f u e l}}{\dot{m}_{f u e l}} \\
& n_{2}(t)=\frac{\dot{n}_{C O_{2}}(t) M_{\text {fuel }}}{\dot{m}_{f u e l}}=\frac{\left(X_{C_{2}}^{A}\left(1-X_{H_{2} O}\right) \dot{n}_{e}-X_{C O_{2}}^{A^{O}}\left(1-X_{H_{2} O}^{O}\right) \dot{n}_{a}\right) M_{f u e l}}{\dot{m}_{f u e l}}
\end{aligned}
$$

The equations for $n_{3}, n_{4}, n_{5}$ are similar to $n_{2}$, but the species have to be changed. By determining the heat of reaction, $\Delta H_{\text {reaction }}$ from the heats of formation of each species taking part, the energy constants from the chemistry during this interval can then be evaluated:

$$
E_{O_{2 c h}}=\frac{\Delta H_{\text {reaction }} M_{\text {fuel }}}{n_{1} M_{O}}
$$

$$
E_{C O_{c h}}=\frac{\Delta H_{\text {reaction }} M_{\text {fuel }}}{n_{3} M_{C O}} \quad(20) \quad E_{\mathrm{CO}_{2} \text { ch }}=\frac{\Delta H_{\text {reaction }} M_{\text {fuel }}}{n_{2} M_{\mathrm{CO}}}
$$

The uncertainty created by the assumptions involving average energy constants when evaluating the HRR of an unknown material is a fundamental concern. To first examine the consistency of the calorimetric equations using the common assumptions, two well studied materials for HRR were tested as reference to evaluate the energy constant estimation methods. These were methane and PMMA. The HRR were calculated using average values (Table 1), stoichiometric $\left(E_{O_{2 s t}}, E_{C_{2} \text { st }}\right.$ and $\left.E_{C O_{s t}}\right)$ and chemical values ( $E_{\mathrm{O}_{2} \mathrm{ch}}, E_{\mathrm{CO}_{2 c h}}$ and $E_{\mathrm{CO}_{c h}}$ ) as energy constants as outlined before. The results of these comparisons show the degree of convergence between mass loss, thermal balance, OC and CDG principles. The distributions also emphasize the differences defining energy constants based on the reaction chemistry rather than using averaged values for a wide range of fuels. Finally, experiments have been performed for a set of complex 
products. Given the assumed reliability of Thornton's principle, OC calorimetry will be assumed as a reference using the average energy constant $E_{\mathrm{O}_{2}}$ obtained previously in Table 1. The energy constant $E_{\mathrm{CO}_{2}}$ will be determined in order to correlate the $\mathrm{OC}$ with $\mathrm{CDG}$ results. The potential importance of the chemistry will be highlighted according to the distribution of fitted $E_{\mathrm{CO}_{2}}$ values around the average.

\section{HRR ESTIMATIONS FOR METHANE}

Any method used to determine the HRR for a given material, should theoretically, produce fairly the same results. To verify this assumption, the HRR for a methane test has been estimated. Methane gas was chosen because of the considerable information available in respect of its combustion processes. It allows checking the accuracy of the calculation methods. Fig. 2 depicts the heat release rates curves that have been calculated from different approaches.

Fig. 2 clearly shows good correlation between OC and mass loss results. Calculations with the average values slightly overestimate the HRR obtained by means of the heat of combustion and mass flow of methane. The relative standard deviation varies around 15\%. The HRR calculations using stoichiometric and chemical energy constants converge with $Q_{\text {mass loss }}$. The relative standard deviation is lower, between 5 and $10 \%$. It has to be noted that the energy constant estimated by assuming the stoichiometry and the ones determined given the chemical reaction are almost identical (respectively 12.5 and $12.42 \mathrm{~kJ}^{-g^{-1}}$ of $\mathrm{O}_{2}$ ). In well ventilated conditions, the reaction follows the stoichiometry for complete combustion, so the amount of $\mathrm{CO}$ produced is negligible and $E_{\mathrm{O}_{2,1}} \approx E_{\mathrm{O}_{2} c h}$. The two last constants, supposing they better account for the actual energy released per unit mass of $\mathrm{O}_{2}$ consumed, are a little lower than the average ones which explains the slight overestimation of $Q_{O C_{\text {Averae }}}$ compared to $Q_{\text {mass loss }}$.

Considering the CDG calorimetry, $Q_{C D G_{\text {nevene }}}$ is significantly lower than $Q_{\text {mass loss }}$. The relative standard deviation is about $30 \%$. Meanwhile HRR estimations with stoichiometric and chemical energy constants converge with $Q_{\text {mass loss }}$. The only difference between the 3 calculations is the energy constants. Analysing their values, reveals, that the results obtained from the average constants are almost $30 \%$ lower than the ones obtained from stoichiometry and chemistry (which are very close for the same reason as the one explained for OC). Given the uncertainty related with the different variables of the equations, the large underestimation of the HRR by $Q_{C D G_{\text {Avere }}}$ is caused by the average energy constants that appear to be inappropriate in the case of methane.

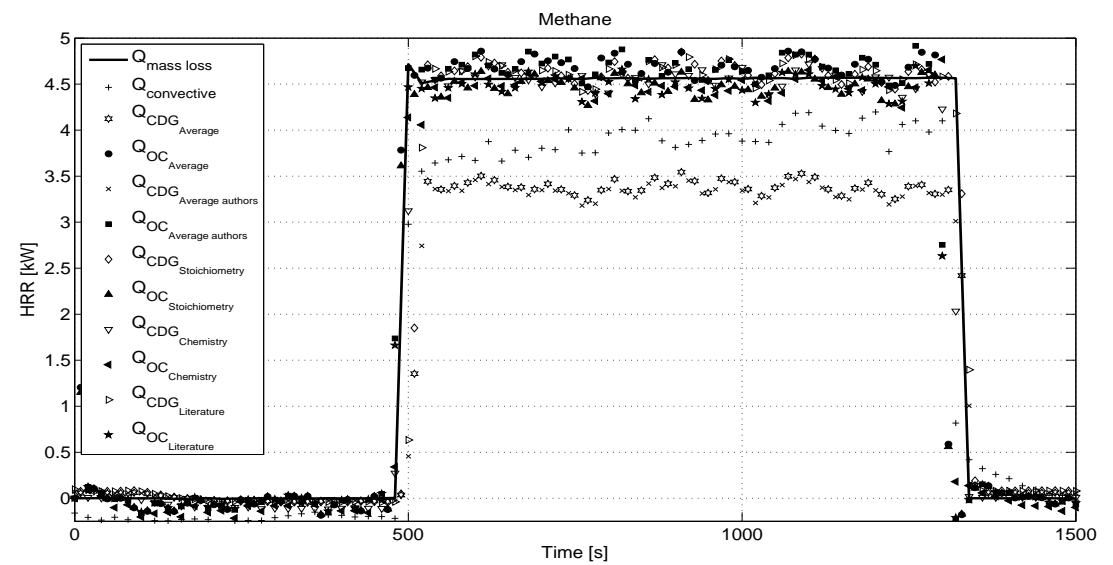

Fig. 2. Obtained HRRs for Methane using different calculation techniques.

In conclusion, if methane gas was involved in a fire without having been identified, OC based on average energy constants would lead to quite accurate HRR results, CDG outcomes also based on average energy 
constants would significantly underestimate it. Fig. 2 shows this clearly. Therefore, the applicability of CDG principle relies in this case on the knowledge of the gas chemistry.

\section{HRR ESTIMATIONS FOR NON STANDARD MATERIALS}

\section{PMMA}

To further assess the HRR calculation methodology based on OC and CDG calorimetry, a more complex combustion problem is chosen where, nevertheless, a significant amount of information is readily available in the literature. The chosen material was the solid PMMA (PolyMethylMethAcrylate). Fig. 3 depicts the various HRR curves that have been calculated through different approaches. Fig. 3 shows that except for the convective HRR ( $\left.Q_{\text {convective }}\right)$, the HRR results are relatively close, whichever the calorimetric method or the energy constants used. As for the methane, it has to be pointed out that stoichiometric and chemical energy constants are almost identical. This is based on the fact, that only an insignificant amount of $\mathrm{CO}$ is produced, thus the chemical reaction follows a complete combustion process. Considering OC calorimetry, $Q_{O C_{\text {Areage }}}$ and $Q_{O C_{\text {Soctinemer }}}$ present good agreement with the $Q_{\text {mass loss }}$. Stoichiometric and average energy constants are very close, therefore the HRRs converge. The relative standard deviation with $Q_{\text {mass loss }}$ excluding the end of the decreasing part of the curves is about $5 \%$.

The highest deviation from the $Q_{\text {mass loss }}$ is obtained with the CDG calorimetry using average energy constants but it remains relatively low (about 13\%). The peak HRR with average energy constants is about $10 \%$ higher than the one obtained from the mass loss calculation while it is underestimated (less than $5 \%$ ) with stoichiometric energy constants. The decreasing part of the curves whatever the CDG assumptions used is lower than the $Q_{\text {mass loss }}$ values. This is speculated to be caused by the relatively long response time of the $\mathrm{CO}_{2} / \mathrm{CO}$ analyser. A correction has been applied based on the same time constant whether the signal rises or decreases. However, the device appears to react faster when the signal decreases (i.e. smaller time constant for the decline) which results in an underestimation of $\mathrm{X}_{\mathrm{CO}_{2}}$. For the rising part and the start of the decrease, the HRR calculated with stoichiometric energy constants reveals a better convergence with $Q_{\text {mass loss }}$ than the HRR evaluated with average energy constants.

The species based calorimetry and the mass loss principle lead to good overall results and comparable results. A significant improvement in respect to a method interchangeable is achieved when using the stoichiometric energy constants for the CDG principle. It can be concluded, for a fire involving PMMA, not knowing the composition of the burning material would not be a critical issue.

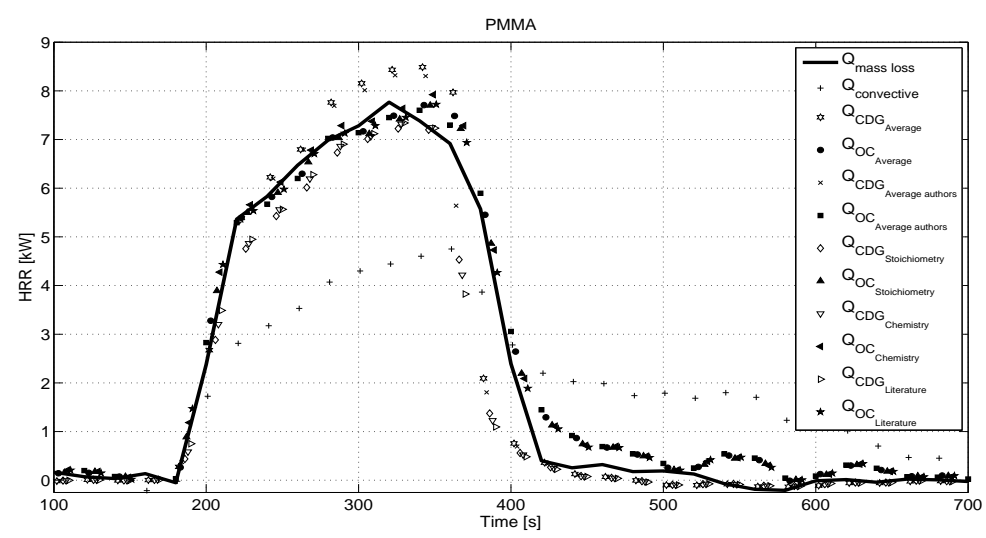

Fig. 3. HRR Calculations for PMMA. 
In the case of the two previous test species, methane and PMMA, OC calorimetry provides relative accurate results when average energy constants are used. At least for these two products, the knowledge of their chemical composition is not a required condition in order to estimate the HRR. On the other hand, CDG calorimetry seems to be more complex. Fig. 2 illustrates for methane the deviation between $Q_{C D G_{\text {Arroga }}}$ and $Q_{\text {mass loss }}$. Average energy constants would clearly lead to significant errors in the HRR estimation. Knowledge about the combustion chemistry of a fuel allows to significantly improve the accuracy of the HRR by means of e.g. the use of stoichiometric or chemical energy constants (see Fig. 3 and Fig. 4).

\section{Unknown and/or complex materials:}

For unidentified materials obtaining the HRR falls back to calorimetry. Given the limitation of the thermal methodology ( $Q_{\text {convective }}$ ), OC and CDG appear as the most eligible techniques. Calculations with average energy constants could be sufficient to obtain accurate HRR estimations even if, as previously shown, knowing the chemistry is advantageous. However, it is sometimes not possible to know what kind of material(s) is (are) actually burning or what chemistry is involved in the combustion process. An obvious example is a room fire where furniture made of different components is present. Other materials have an inherent potential for being complex in their combustion process, such as engineered materials with fire retardants (FR) and with nanocomposites (NC) or energetic materials. The degree of complexity however is not necessarily manmade. Nature itself also provides us with, combustion wise, complex materials such as wood and pine needles. It is difficult to characterize and to define energy constants for these products given most of the intricacies about their decomposition chemistry still has to be understood.

For the practical application, it is important to know if the calorimetric equations can be applied using average values for the energy constants or if knowing their chemistry is a required condition in order to estimate their HRR. To assess this question, a mix of different materials has been studied: PolyMethylMethacrylate (PMMA), Polypropylene (PP), Polybutylene (PBT), Nylon (PA6), Pine needles (Pinus pinaster $\left(\mathrm{PH}^{*}\right)$, Pinus halepensis $(\mathrm{PH})$ ) and energetic powders (Ternary mixture of starch, lactose and $\mathrm{KNO}_{3}$ ). A comparison of HRR results from OC and CDG analysis using average energy constants, energy constants calculated from heats of combustion found in the literature, and by assuming the stoichiometry of the combustion reaction has been conducted. Using the later, better convergence is achieved but further improvement would be beneficial. The authors have opted not to show the HRR comparisons but instead present the distribution of the energy constants calculated by assuming the stoichiometry. Fig. 4 shows the energy constants $E_{\mathrm{O}_{2}}, E_{\mathrm{CO}_{2}}$ and $E_{\mathrm{CO}}$ for the mentioned materials. The averages of the distributions are calculated and compared to the average energy constants from the

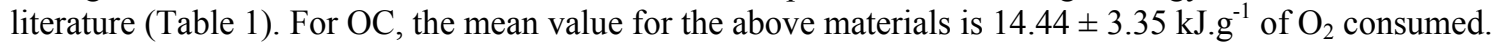
It is higher than Huggett's average value. This mainly stems from the energetic powders that carry an oxidizer $\left(\mathrm{KNO}_{3}\right)$. It supplies the combustion reaction with additional $\mathrm{O}_{2}$ which is not accounted for in the original calorimetric equations, leading to a higher energy constant per unit mass of $\mathrm{O}_{2}$ consumed. When excluding these 2 materials, the averaged energy constant falls to $12.7 \mathrm{~kJ}^{-g^{-1}}$ of $\mathrm{O}_{2}$ which is closer to the one obtained from the literature. The energy release constant per unit mass of $\mathrm{CO}_{2}$ generated $\left(E_{\mathrm{CO}_{2}}\right)$ is less scattered and e.g. independent of the existence of $\mathrm{O}_{2}$ in the material. The materials of interest have an average value of $11.01 \pm 1.23 \mathrm{~kJ} / \mathrm{g}$ per $\mathrm{CO}_{2}$ generated. It is significantly lower than Tewarson's value as well as the one presented in Table 1 . 

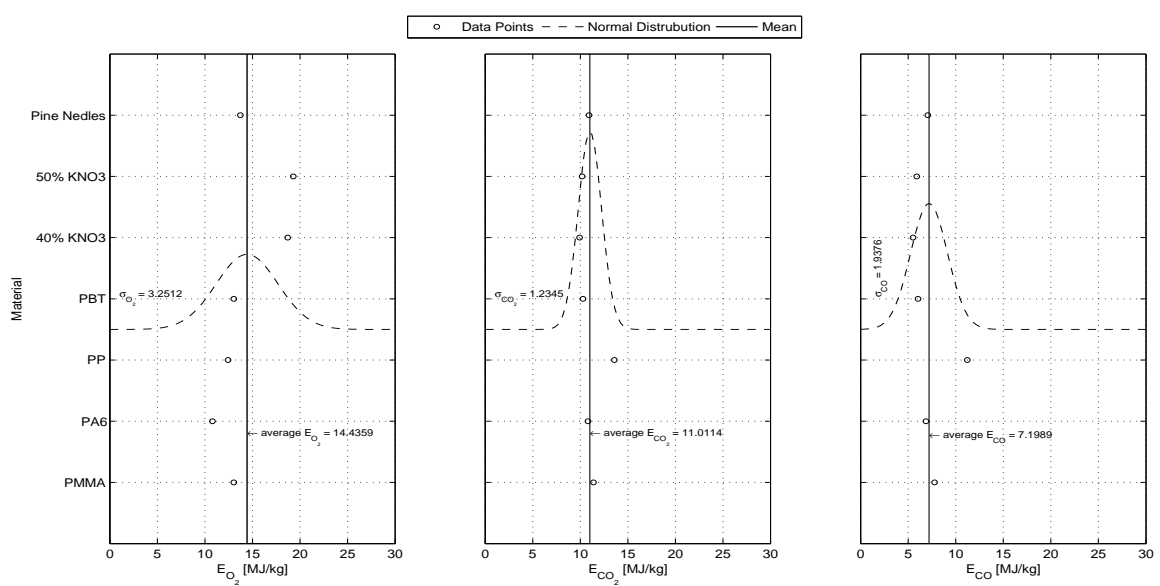

Fig. 4. Energy Constants distribution for a bunch of 7 known materials.

Being able to depict differences between the HRR obtained via OC and CDG calorimetry, the authors have developed the following approach. Theoretically OC and CDG should provide, for the same material and test, the same HRR. By setting the energy constant of the OC calorimetry to be to $13.1 \mathrm{MJ} / \mathrm{kg}$ (as depicted in Table 1), it is possible to determine $E_{\mathrm{CO}_{2}}$ values to arrive at a convergence between the 2 methods by minimising the surmised differences of the two curves. The obtained $E_{\mathrm{CO}_{2}}$ results for the various complex materials are presented in Fig. 5. It is important to point out, that the deviations do not show the error of one method above the other but shows the differential error of the two methodologies for the same material and test. Furthermore, for the here presented materials the mean, the standard deviation $(\sigma)$ and normal distribution are added to the graph as well as the previously obtained mean value of all the data found in literature now called average.

Fig. 5 shows fitted $E_{\mathrm{CO}_{2}}$ values so that the CDG HRR curve converges with the OC HRR curve fixing the energy constant $E_{\mathrm{O}_{2}}$ to $13.1 \mathrm{MJ} / \mathrm{kg}$ per unit mass of $\mathrm{O}_{2}$ consumed. To prove the validity of the average energy constant assumption, the $E_{\mathrm{CO}_{2}}$ values should only slightly deviate from the average literature value

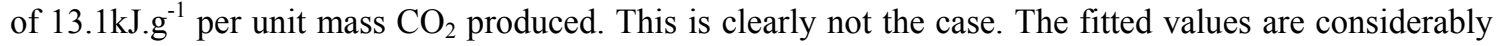
scattered, the distribution is too large to be able to define a consistent average energy constant.

For unknown complex materials such as the ones under investigation here, the common average energy constants could lead to significant errors in the HRR estimation. It is possible that one or the other methodology would provide the more accurate result, but which one, is unknown and depends on the material and test conditions. Each method has its advantages and disadvantages as presented earlier. Some can not be used accurately for unknown materials. The use of OC and CDG based on the assumption of usual average energy constants can clearly provide unreliable results, if unreliability is stated as the non convergence. For known materials, a convergence criterion can be achieved if the compound decomposition is known and if energy constants are calculated based on the stoichiometric reaction for complete combustion or the actual chemical reactions where coefficients are evaluated from the species consumption $\left(\mathrm{O}_{2}\right)$ and production $\left(\mathrm{CO}_{2} / \mathrm{CO}\right)$. 


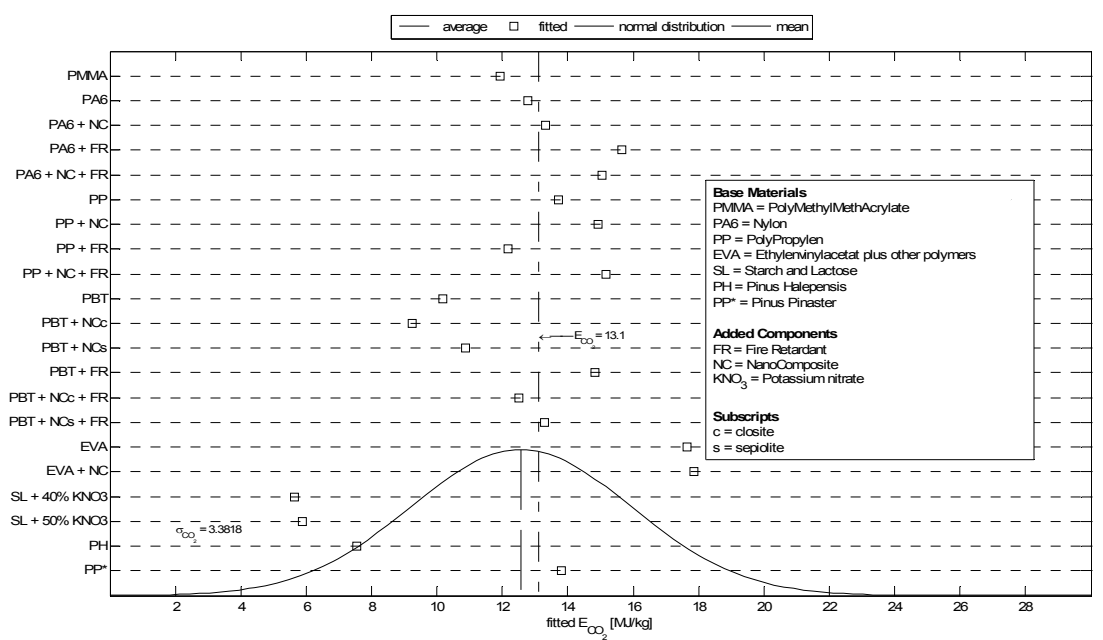

Fig. 5. Comparison data for $\mathrm{E}_{\mathrm{CO}_{2}}$ for various compounds.

\section{CONCLUSION}

The main advantage to determine the HRR curves by the two calorimetric principles: oxygen consumption (OC) and carbon dioxide generation (CDG) via assumed (average) energy constants is the fact, that they do not require any knowledge of the burning fuel. Theoretically both principles should produce relatively similar results; this however, as presented in Fig. 5 does not always seem to be the case. Uncertainty analysis $[10,11,12]$ showed that knowing the composition of the burning material significantly decreases the error in the HRR calculations. The task is to define how much of the chemistry of a material is required to obtain a reliable estimation of the HRR. To determine that PMMA and Methane tests have been carried out. Here the OC and CDG HRR are in agreement when energy constants obtained from the literature or calculated ones are being used. The later is based on the composition of the material and/or the chemistry of the combustion reaction. Averaged constants however lead to deviation. To broaden the view and to determine real world practicality the problem was extended to new/unknown and potentially complex materials (polymers with nanocomposites and/or fire-retardant, powders containing an oxidizers and pine needles). Based on the theoretical criterion that the released heat obtained from different methods should provide the same result for any given point in time, a comparison of OC and CDG to obtain the HRR of various test specimen shows, that in the here presented cases, average energy constants usually lead to significant deviations from each others HRR. Since a "real" HRR reference for new/complex materials is usually not available, assuming the correctness of one above the other is not possible. It appears that converging results using OC and CDG calorimetry by assuming average energy constants can not usually be obtained for materials with complex combustion processes. Why that is the case and possibly to correct for it requires further research. Nevertheless the dispersion underlines the dependence of the calorimetric methods to the knowledge of the chemistry of the materials in order to assess their heat release rates.

\section{REFERENCES}

[1] Standard Test Method for Heat and Visible Smoke Release Rates for Materials and Products, ASTM E-906, American Society for Testing and Materials, Philadelphia, 1983.

[2] Fire Tests - Reaction to Fire - Part 1: Rate of Heat Release from Building Products (Cone Calorimeter), ISO 5660, International Standards Organisation, Geneva, 1993.

[3] Standard Test Method for Heat and Visible Smoke Release Rates for Materials and Products Using an Oxygen Consumption Calorimeter, ASTM 1354-905, American Society for Testing Materials, Philadelphia, 1995. 
[4] Walters, R.N., Lyon, R.E., A Microscale Combustion Calorimeter for Determining Flammability Parameters of Materials, Proc. Int. SAMPE Symposium and Exhibition 42 (2) (1997), 1335 1344.

[5] Babrauskas, V., The Cone Calorimeter, SFPE Handbook of Fire Protection Engineering, 3rd edition, Section 3 - Chapter 3, The National Fire Protection Association Press, Boston, 2002.

[6] Heskestad, G., A Fire Products Collector for Calorimetry into the MW Range, FMRC J.I. 0CE1.RA, FM-Global, Norwood, 1981.

[7] Thornton, W., The Relation of Oxygen to the Heat of Combustion of Organic Compounds, Philosophical Magazine 33 (1917), 196 - 203.

[8] Huggett, C., Estimation of Rate of Heat Release by Means of Oxygen Consumption Measurements, Fire and Materials 4 (2) (1980), 61 - 65. doi:10.1002/fam.810040202

[9] Tewarson, A., Generation of Heat and Chemical Compounds in Fires, SFPE Handbook of Fire Protection Engineering, 3rd edition, Section 3 - Chapter 4, The National Fire Protection Association Press, Boston, 2002, 3-82 - 3-161.

[10] Enright, P. A., Fleischmann, C. M., Uncertainty of Heat Release Rate Calculation of the ISO5660-1 Cone Calorimeter Standard Test Method, Fire Technology. 35, No. 2, 153-169, (1999). doi:10.1023/A:1015416005888

[11] Axelsson, J., Andersson, P., Lönnermark, A., Van Hees, P., Wetterlund, I., Uncertainties in Measuring Heat and Smoke Release Rates in the Room/Corner Test and the SBI, SP Swedish National Testing and Research Institute, NT Technical Report 477, NORDTEST Project No. 1480-00, SP Report 2001:04.

[12] Brohez, S., Uncertainty analysis of heat release rate measurement by oxygen consumption calorimetry, Fire and Materials 29 (2005), 383-394. doi:10.1002/fam.895

[13] Janssens, M., Uncertainty of Fire Test Results, Interflam07 (2007).

[14] Taylor, J., R. An Introduction to Error Analysis, University Sciences Books, $2^{\text {nd }}$ Edition, 1997.

[15] Smith, E., E., Heat Release Rate Calorimetry, Fire Technology 32 (1996), 333 - 347. doi:10.1007/BF01037743

[16] Standard Test Method for Measurement of Synthetic Polymer Material Flammability Using a Fire Propagation Apparatus, ASTM E2058-03, American Society for Testing Materials, Philadelphia, 2003.

[17] Janssens, M. L., Parker, W.J., Babrauskas (Ed.), V., Heat Release in Fires, Elsevier Applied Science, London, 1992, pp31-59.

[18] Parker, W.J, Calculations of the Heat Release Rate by Oxygen Consumption for Various Applications, Journal of Fire Sciences 2 (1985), 380-395. doi:10.1177/073490418400200505

[19] Standard Test Method for Gross Calorific Value of Coal and Coke by the Adiabatic Bomb Calorimeter, ASTM D 2015, American Society for Testing and Materials, Philadelphia, 1991.

[20] Walters, R.N., Hackett, S.M.; Lyon, R.E., Heats of Combustion of High-Temperature. Polymers, Fire and Materials 24 (5) (2000), pp.245-252. doi:10.1002/10991018(200009/10)24:5<245::AID-FAM744>3.0.CO;2-7

[21] Janssens, M., Calorimetry, SFPE Handbook of Fire Protection Engineering, 3rd edition, Section 3 - Chapter 2, The National Fire Protection Association Press, Boston, 2002. 